\title{
A Nested Case Control Study of the Abdominal Wound Dehiscence in a Rural Hospital in South India
}

\author{
Dr Mohana Murali Krishna N ${ }^{1}$, Dr K.Sudheer Kumar², Dr G.Lakshman Prasad ${ }^{3}$ \\ ${ }^{I}$ Dr Mohana Murali Krishna N, DNB., (General Surgery), DNB Resident, Rural Development Trust Hospital, \\ Bathalapalli, Ananthapur Dist, Andhra Pradesh, India. \\ ${ }^{2}$ Dr Katumalla Sudheer Kumar,M.S., (General Surgery), Senior Consultant, Rural Development Trust Hospital, \\ Bathalapalli, Ananthapur Dist, Andhra Pradesh, India. \\ ${ }^{3}$ Dr G.Lakshman Prasad, M.S., (General Surgery), Senior Consultant, Rural Development Trust Hospital, \\ Bathalapalli, Ananthapur Dist, Andhra Pradesh, India.
}

\begin{abstract}
The abdominal wound dehiscence is defined as partial or complete separation of the fascial layers of the abdomen. Also been described as fascial dehiscence, postoperative eventration, abdominal wound disruption, broken-down abdominal wounds and burst abdomen. The incidence rate mentioned in the international literature ranges from 0.4-3.5\%. The reported mortality rates of the complication are as high as $45 \%$ associated with the severity.

In our teaching hospital which is a Secondary level hospital in a rural area, an overall incidence of 6\% of abdominal wound dehiscence is observed in comparison to others.

In this study, many risk factors were observed to be the cause for the development of abdominal wound dehiscence. Many of the patient related risk factors were proved to be the cause for the development of dehiscence. Hypoproteinemia, Anaemia, Renal failure, uremia, presence of malignancy, associated diseases like Diabetes, hypertension, COPD and immunocomprimised state of the patient, factors which increase intra abdominal pressure like post operative cough, vomiting, abdominal distension and urine retention, development of the wound infection plays a role in the development of wound dehiscence.
\end{abstract}

Keywords: Dehiscence, eventration, factors

\section{Introduction}

The abdominal wound dehiscence is one of the most important complications faced by a surgeon. It is defined as partial or complete separation of the fascial layers of the abdomen. Also been described as fascial dehiscence, postoperative eventration, abdominal wound disruption, broken-down abdominal wounds and burst abdomen. The incidence rate mentioned in the international literature ranges from 0.4-3.5\%. The reported mortality rates of the complication are as high as $45 \%$ associated with the severity ${ }^{1,2}$.

The management of wound dehiscence cases creates difficulties for both a surgeon as well as for a patient too. It ranges from a simple separation of fascial layers to complete evisceration.

Abdominal dehiscence can be categorized into partial and complete types. Partial dehiscence is separation of one or more fascial layers while the skin or peritoneum either of them is intact. Complete dehiscence is described as separation of whole of all layers of abdominal wall but it may or may not be associated with evisceration. Wound dehiscence is of greatest concern when it is associated with evisceration which is protrusion of bowel out through the abdominal incision.

There are several risk factors which are responsible for the development of wound dehiscence and they can be classified into patient factors and surgeon related factors. Emergency surgery, faulty abdominal wall closure, malnutrition, obesity, anemia, jaundice, uremia, malignancy, use of steroids, diabetes, wound infection, post operative cough, vomiting, paralytic ileus, abdominal distension are important among the proposed risk factors.

Death is not caused by the dehiscence per se but this complication contributes to an excessive mortality in these patients, who are usually elderly having wound infection, chest diseases, malignancy and other associated medical problems. So identifying the risk factors which contribute to the development of abdominal wound dehiscence is a responsibility of surgeon to help early recovery of the patient.

Most of the data available is urban based and there are fewer amounts of data regarding the wound dehiscence in a rural level hospital. Patients who are residents in rural India are more prone for nutritional impairment due to the pertaining poverty and illiteracy.

This study was conducted in a secondary level hospital situated in a rural area in southern India, where poverty and malnourishment are more common, and access to the health care in emergency conditions is not readily available. This study helps in assessing the extent of the problem and identifying the risk factors associated with abdominal wound dehiscence in our hospital. It helps in identifying the patients who are at risk 
of developing wound dehiscence, so that they can be given better care and subsequently can reduce the incidence, morbidity and mortality associated with the wound dehiscence.

This study helps in undertaking various prophylactic measures that will help in preventing the development of the wound disruption.

\section{Aim And Objectives}

1. To identify risk factors in patients developing abdominal wound dehiscence.

2. To calculate the incidence of abdominal wound dehiscence and to estimate the extent of problem in our hospital.

\section{Materials And Methods}

3.1 Study site:

Rural Development Trust hospital, a 330 bedded secondary level hospital

\subsection{Study duration:}

December 2013 to May 2015

3.3 Study design:

A Nested Case control study

\subsection{Study criteria:}

i. Inclusion criteria

All patients who underwent elective and emergency surgeries during the period of two years were included in the study.

\section{ii. Exclusion criteria}

$\checkmark \quad$ Patients below the age of 3 years were excluded from the study.

$\checkmark \quad$ Patients who died during the study period were also excluded from the study.

\subsection{Sample size:}

Sample size was calculated using following formula. Calculated sample size was 36 , but during the study period only 30 subjects developed burst abdomen.

$$
n=2 \frac{\left(p^{\prime}\right)\left(q^{\prime}\right)\left(Z_{\alpha}+Z_{\beta}\right)}{\left(\mathrm{p}_{1}-p_{0}\right)^{2}}
$$

\subsection{Study procedure:}

a. Cases:

All the patients who developed wound dehiscence were taken as cases.

\section{b. Controls:}

To increase the power of study, 3 controls were selected for each case from the study subjects who were at risk at the time of occurrence of wound dehiscence in a case. Cases and controls were selected and matched based on baseline characteristic variables. A control that subsequently developed dehiscence was also considered as a case. A cohort subject may be selected as a control for more than one case.

\section{c. Pre operative data}

A detailed clinical history was taken regarding the disease. The clinical findings were noted. All necessary laboratory investigations underwent preoperatively were also collected.

\section{d. Intra operative and post operative findings}

$\checkmark \quad$ Intra operative data and post operative data was collected. Detailed description of the format is discussed below.

$\checkmark$ Patients were observed for wound site infections and subsequently followed up with the culture and sensitivity reports.

$\checkmark$ Post operatively the biopsy reports were followed and accordingly the final diagnosis was noted.

$\checkmark \quad$ The day of dehiscence, day of discharge and condition of the patient during discharge were also recorded. 


\section{e. End points:}

Risk factors contributing to the development of wound dehiscence were the end points.

\subsection{Statistical analysis:}

$\checkmark$ Baseline characteristics were analyzed and calculated by descriptive statistical analysis using MS-Excel 2007

$\checkmark$ Association between risk factors and development of wound dehiscence in cases were analyzed using Instat Graph Pad version 3.01, 32bit

$\checkmark \quad P$ value less than 0.05 was considered as statistically significant

$\checkmark$ Incidence rate of abdominal wound dehiscence was calculated by

$$
\text { Incidence Rate }=\frac{\text { No. of new cases }}{\text { Population at risk }}
$$

$\checkmark$ Chi-square test was calculated further with Yate's continuity correction

$\checkmark \quad 95 \%$ CI was calculated using the approximation of Woolf

\section{Results}

Table 1: Overview of results with respect to the variables included in proforma

\begin{tabular}{|c|c|c|c|}
\hline \multicolumn{2}{|c|}{ Variable } & Cases & Controls \\
\hline \multirow[t]{4}{*}{ Age } & 03-20 years & 04 & 06 \\
\hline & $20-40$ years & 09 & 26 \\
\hline & 40-60years & 16 & 52 \\
\hline & $>60$ years & 01 & 06 \\
\hline \multicolumn{2}{|c|}{ Gender } & 12 & 36 \\
\hline \multicolumn{2}{|c|}{ Females } & 18 & 54 \\
\hline \multicolumn{2}{|c|}{ Under weight } & 07 & 23 \\
\hline \multicolumn{2}{|c|}{ Normal } & 13 & 54 \\
\hline \multicolumn{2}{|c|}{ Over weight } & $\mathbf{0 3}$ & 09 \\
\hline \multicolumn{2}{|c|}{ Obese } & 07 & 04 \\
\hline \multicolumn{2}{|c|}{ X-ray changes } & 13 & 10 \\
\hline \multicolumn{2}{|c|}{ Emergency } & 25 & 70 \\
\hline \multicolumn{2}{|c|}{ Elective } & 05 & 20 \\
\hline \multicolumn{4}{|c|}{ Type of Incision } \\
\hline \multicolumn{2}{|c|}{ Transverse } & -- & 05 \\
\hline \multicolumn{2}{|c|}{$\begin{array}{l}\text { Wound class } \\
\text { Clean }\end{array}$} & -- & 08 \\
\hline & ean contaminated & 05 & 40 \\
\hline \multicolumn{2}{|c|}{ Contaminated } & 10 & 32 \\
\hline \multicolumn{2}{|c|}{ Dirty } & 15 & 10 \\
\hline \multicolumn{2}{|c|}{ Presence of Tension sutures } & 15 & 21 \\
\hline \multicolumn{2}{|c|}{ Post Op binder } & 10 & 11 \\
\hline \multicolumn{2}{|c|}{ Presence of stoma } & 10 & 08 \\
\hline & $\begin{array}{r}\text { Comorbidities } \\
\text { Diabetic }\end{array}$ & 10 & 06 \\
\hline \multicolumn{2}{|c|}{ Hypertensive } & -- & 04 \\
\hline \multicolumn{2}{|c|}{ Malignant } & 10 & 08 \\
\hline \multicolumn{2}{|c|}{ HIV } & 03 & 04 \\
\hline \multicolumn{2}{|c|}{ TB } & -- & 02 \\
\hline \multicolumn{2}{|c|}{$\begin{array}{r}\text { Personal history } \\
\text { Smoking }\end{array}$} & 15 & 21 \\
\hline \multicolumn{2}{|c|}{ Alcohol } & 10 & 21 \\
\hline
\end{tabular}

Results of individual risk factors are calculated and mentioned below.

Incidence :Approximately 500 laparotomies were done in Rural Development trust Hospital during our study period. Out of them, 30 cases developed abdominal wound dehiscence.

Table 2: Table showing incidence of our hospital

\begin{tabular}{|l|l|l|}
\hline Total laparotomies & Wound dehiscence cases & Incidence \\
\hline 500 & 30 & $6 \%$ \\
\hline
\end{tabular}


An incidence of $6 \%$ was recorded in our study. According to literature, the incidence of wound dehiscence ranges from $0.4 \%$ to $3.5 \%$.

Age

A total of 120 subjects were taken into the study from the selected cohort. Of them, 30 subjects developed wound dehiscence and were considered as cases. And remaining subjects who did not develop the dehiscence but has the risk factors for its development were considered as controls. There were 12 males and 18 females in Cases. 36 males and 54 females were there in Controls.

Table 3: Showing different age groups of the study population

\begin{tabular}{|l|l|l|}
\hline Age group & Cases & Percent \\
\hline $03-20$ yrs & 04 & $13.3 \%$ \\
\hline $20-40$ yrs & 09 & $30 \%$ \\
\hline $40-60$ yrs & 16 & $53.4 \%$ \\
\hline$>60$ yrs & 01 & $3.3 \%$ \\
\hline
\end{tabular}

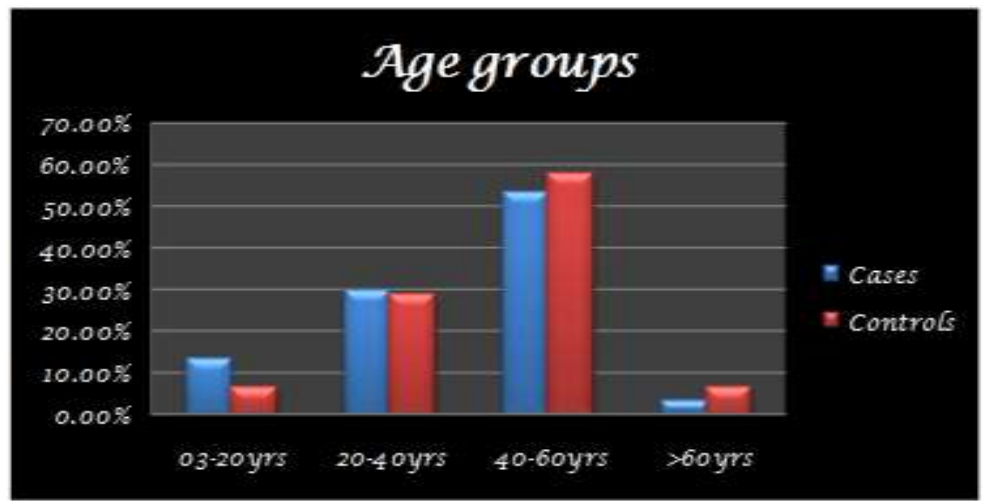

Fig 1: Graph showing the percentage of various age groups

The highest incidence of abdominal wound dehiscence was found to be in age group of 40-60 years, with mean age of 41.2 years.

Table 4: Gender-wise Distribution of study subjects

\begin{tabular}{|l|l|l|}
\hline Subjects & Males & Females \\
\hline Cases & 12 & 18 \\
\hline Controls & 36 & 54 \\
\hline
\end{tabular}
subjects.

In our study, we observed that female subjects developed wound dehiscence more compared to male

Table 5: Obesity as a risk factor

\begin{tabular}{|l|l|l|}
\hline Variable & Cases & Controls \\
\hline Under weight & $07(23.3 \%)$ & $23(25.5 \%)$ \\
\hline Normal & $13(43.3 \%)$ & $54(60 \%)$ \\
\hline Over weight & $03(10 \%)$ & $09(10 \%)$ \\
\hline Obese & $07(23.3 \%)$ & $04(4.4 \%)$ \\
\hline
\end{tabular}

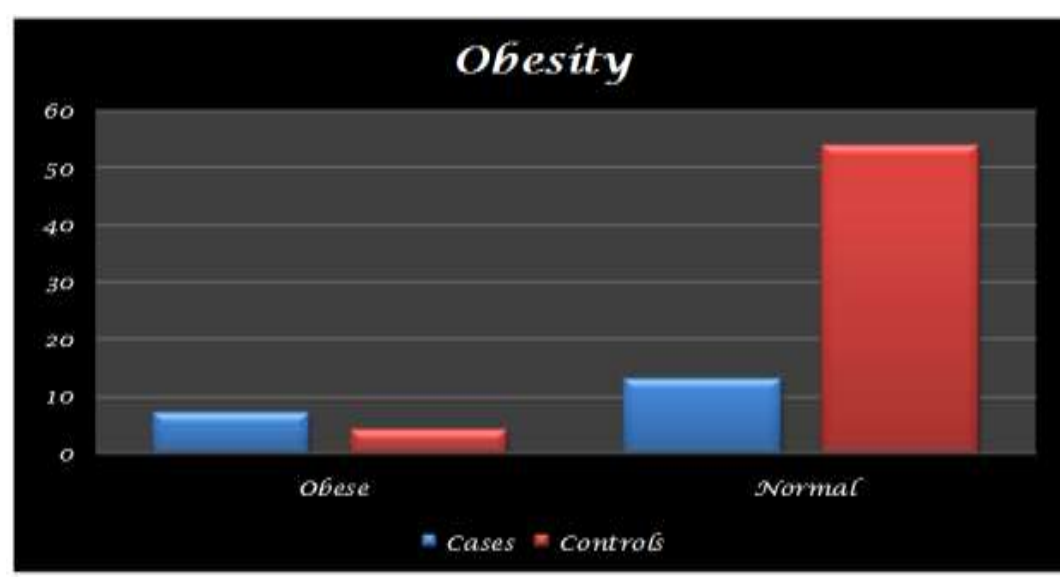

Fig 2: Graph showing the risk of obesity on AWD 


\begin{tabular}{|l|l|l|c|}
\hline Chi square statistic & $\mathrm{p}$ value & Odds ratio & $95 \% \mathrm{CI}$ \\
\hline 7.515 & $\mathbf{0 . 0 0 6 1}$ & $\mathbf{7 . 2 6 9}$ & $\mathbf{1 . 8 4 7}$ to 28.605 \\
\hline \multicolumn{3}{|c|}{ Degree of freedom $=1$} \\
\hline
\end{tabular}

Obesity is said to be one of the risk factor for the development of burst abdomen. p value was found to be $<0.05$ and is considered as statistically significant. The odds ratio obtained also shows positive association between obesity and burst abdomen.

Table 6: Haemoglobin

\begin{tabular}{|l|l|l|}
\hline Variable & Cases & Controls \\
\hline Anemia & $25(83.3 \%)$ & $33(36.6 \%)$ \\
\hline Normal & $5(16.7 \%)$ & $57(63.4 \%)$ \\
\hline
\end{tabular}

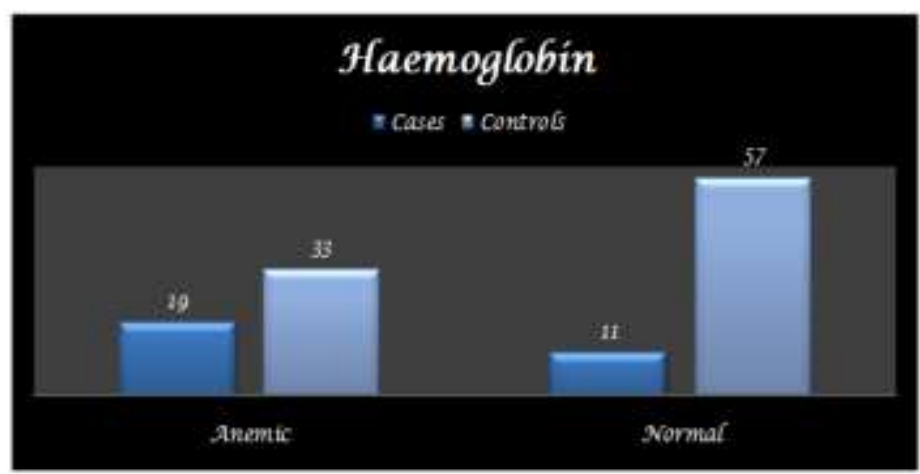

Fig 3: Graph showing the risk of anemia to develop dehiscence

The process of wound healing is dependent upon the status of anemia in patients. Decreased Hb further leads to reduced tissue oxygenation and leads to delay in wound healing process.

WHO classification of anemia

\begin{tabular}{|l|l|l|l|}
\hline Hb level & Mild & Moderate & Severe \\
\hline Males & $11-13 \mathrm{~g} / \mathrm{dl}$ & $8-11 \mathrm{~g} / \mathrm{dl}$ & $<8 \mathrm{~g} / \mathrm{dl}$ \\
\hline Females & $11-12 \mathrm{~g} / \mathrm{dl}$ & $8-11 \mathrm{~g} / \mathrm{dl}$ & $<8 \mathrm{~g} / \mathrm{dl}$ \\
\hline
\end{tabular}

Cases that have the risk factor of anemia were calculated for chi-square statistic, odds ratio and $95 \%$ confidence interval. And they are as follows,

\begin{tabular}{|l|l|l|l|}
\hline Chi square statistic & $\mathrm{p}$ value & Odds ratio & 95\% CI \\
\hline 5.475 & $\mathbf{0 . 0 1 9 3}$ & $\mathbf{2 . 9 8 3}$ & $\mathbf{1 . 2 6 5}$ to $\mathbf{7 . 0 3 4}$ \\
\hline
\end{tabular}

Above values shows statistical significance and positive association between anemia and development of dehiscence.

Table 7: Serum albumin

Malnutrition has significant impact on wound healing. Protein catabolism can result in delay in wound healing process. One of the parameters which can be used for measuring the nutritional status is serum albumin, which plays significant role in wound healing process.

\begin{tabular}{|l|l|l|}
\hline Variable & Cases & Controls \\
\hline Hypoalbuminaemia & $16(53.3 \%)$ & $24(26.7 \%)$ \\
\hline Normal & $14(46.7 \%)$ & $66(73.3 \%)$ \\
\hline
\end{tabular}

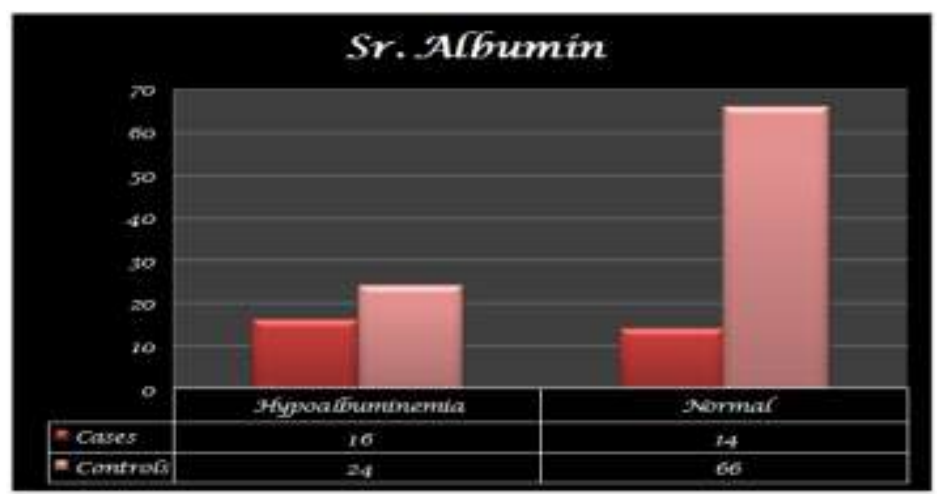

Fig 4: Graph showing the risk of hypoalbuminaemia 
A Nested Case Control Study Of The Abdominal Wound Dehiscence In A Rural Hospital In South...

\begin{tabular}{|l|l|l|l|}
\hline Chi square statistic & $\mathrm{p}$ value & Odds ratio & $95 \%$ CI \\
\hline 6.050 & $\mathbf{0 . 0 1 3 9}$ & $\mathbf{3 . 1 4 3}$ & $\mathbf{1 . 3 3 5}$ to $\mathbf{7 . 3 9 9}$ \\
\hline Degree of freedom $=1$ & \multicolumn{4}{|l|}{} \\
\hline
\end{tabular}

The odds ratio obtained shows that the association between hypoalbunemia and wound dehiscence is positive.

Table 8: Serum Proteins

Since malnutrition has significant impact on wound healing, one of the parameter that can be used for measuring the nutritional status is total proteins.

\begin{tabular}{|l|l|l|}
\hline Variable & Cases & Controls \\
\hline Hypoproteinemia & $21(70.0 \%)$ & $35(38.9 \%)$ \\
\hline Normal & $9(30.0 \%)$ & $55(61.1 \%)$ \\
\hline
\end{tabular}

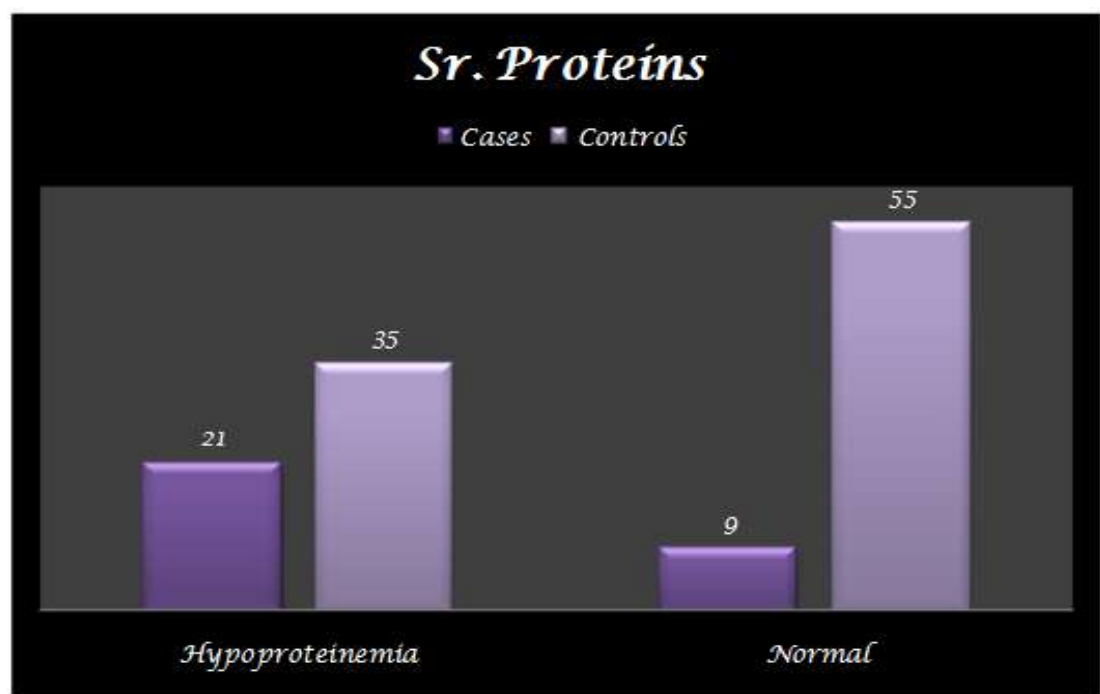

Fig 5: Graph showing the risk of hypoproteinemia

\begin{tabular}{|l|l|l|l|}
\hline Chi square statistic & $\mathrm{p}$ value & Odds ratio & $95 \%$ CI \\
\hline 7.545 & $\mathbf{0 . 0 0 6 0}$ & $\mathbf{3 . 6 6 7}$ & $\mathbf{1 . 5 0 8}$ to 8.917 \\
\hline Degree of freedom $=1$ &
\end{tabular}

Calculated value is $<0.05$ and is considered statistically significant. Even the odds ratio shows positive association between hypoproteinemia and wound dehiscence.

Table 9: Urea

\begin{tabular}{|l|l|l|}
\hline Variable & Cases & Controls \\
\hline Uremia & $16(53.3 \%)$ & $26(28.9 \%)$ \\
\hline Normal & $14(46.7 \%)$ & $64(71.1 \%)$ \\
\hline
\end{tabular}

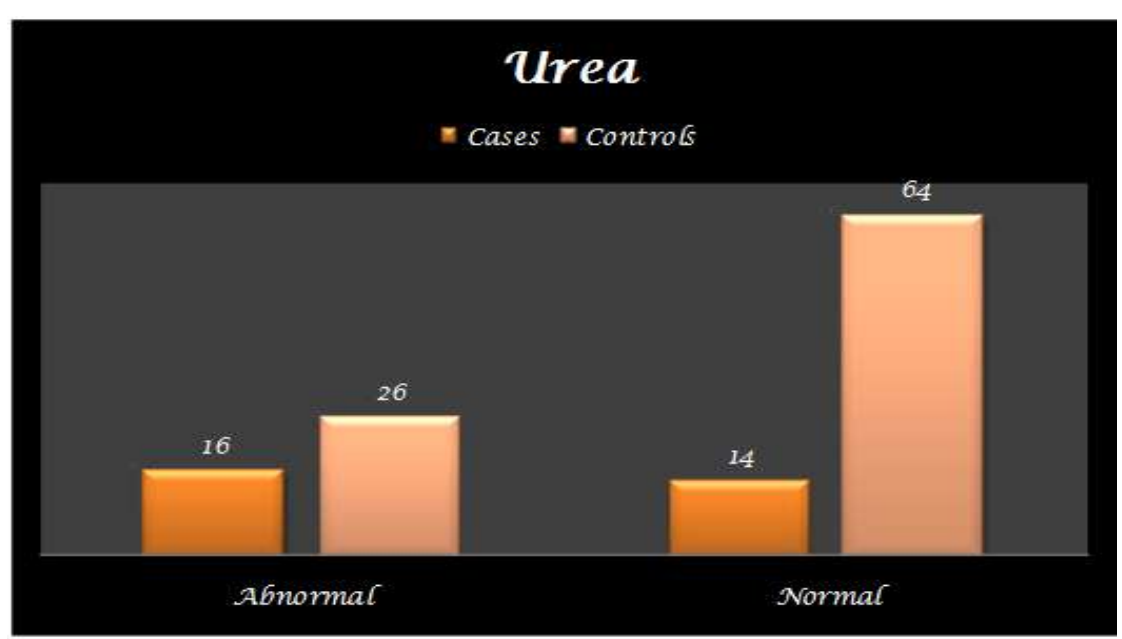

Fig 6: Graph showing the risk of uremia in AWD study population

\begin{tabular}{l|l|l|l}
\hline Chi square statistic & p value & Odds ratio & $95 \%$ CI
\end{tabular}


A Nested Case Control Study Of The Abdominal Wound Dehiscence In A Rural Hospital In South...

\begin{tabular}{|l|l|l|l|}
\hline 4.884 & $\mathbf{0 . 0 2 7 1}$ & $\mathbf{2 . 8 1 3}$ & $\mathbf{1 . 2 0 2}$ to 6.582 \\
\hline Degree of freedom $=1$ & \multicolumn{3}{|l|}{} \\
\hline
\end{tabular}

Obtained $\mathrm{p}$ value shows statistical significance. Value of odd ratio obtained was also $>1$, that shows positive association between risk factor and dehiscence.

Table 10: Renal Failure

\begin{tabular}{|l|l|l|}
\hline Variable & Cases & Controls \\
\hline Renal failure & $19(63.3 \%)$ & $36(40.0 \%)$ \\
\hline Normal & $11(36.7 \%)$ & $54(60.0 \%)$ \\
\hline
\end{tabular}

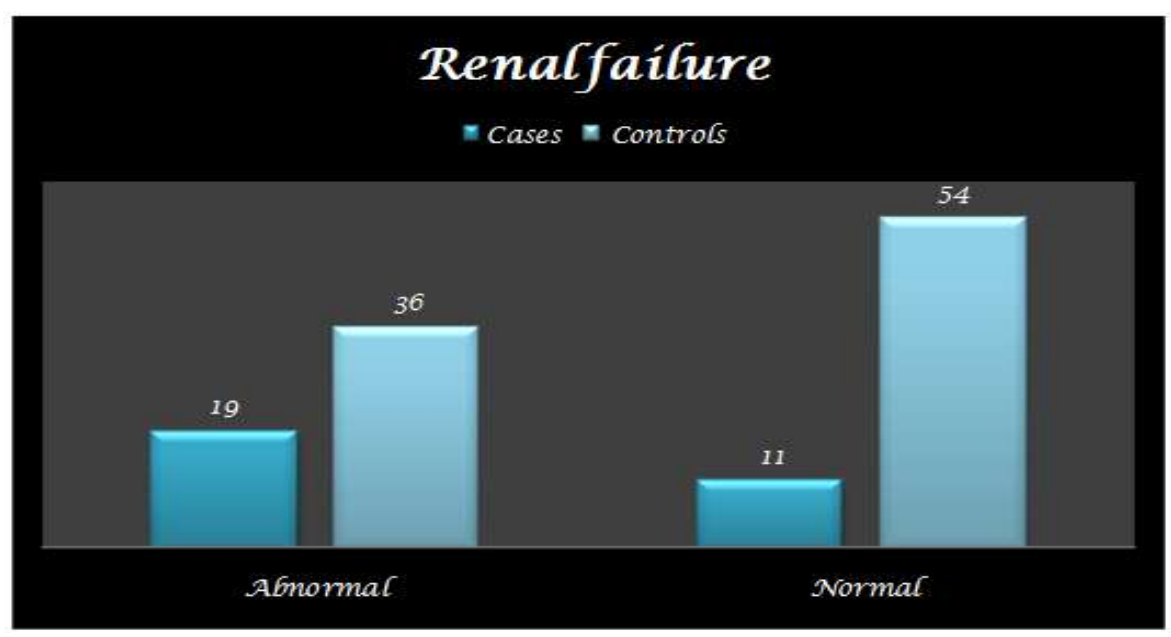

Fig 7: Graph showing the risk of AWD development in renal failure subjects

\begin{tabular}{|l|l|l|l|}
\hline Chi square statistic & $\mathrm{p}$ value & Odds ratio & 95\% CI \\
\hline 4.039 & $\mathbf{0 . 0 4 4 5}$ & $\mathbf{2 . 5 9 1}$ & $\mathbf{1 . 1 0 3}$ to $\mathbf{6 . 0 8 7}$ \\
\hline Degree of freedom $=1$ & \multicolumn{4}{|l}{} \\
\hline
\end{tabular}

The $\mathrm{p}$ value seems statistically significant. Odds ratio is also $>1$, i.e., positive association between high levels of serum creatinine and wound dehiscence development.

Table 11: Lactate

\begin{tabular}{|l|l|l|}
\hline Variable & Cases & Controls \\
\hline Abnormal & $24(80.0 \%)$ & $42(46.7 \%)$ \\
\hline Normal & $6(20.0 \%)$ & $48(53.3 \%)$ \\
\hline
\end{tabular}

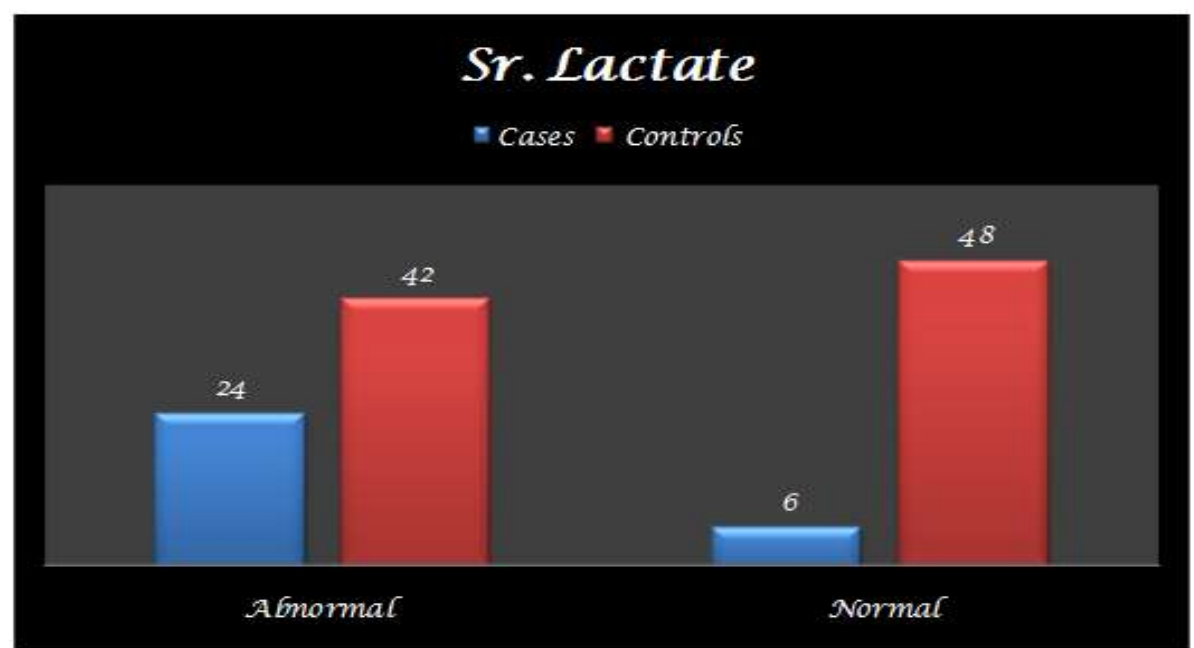

Fig 8: Graph showing the elevated lactate levels as risk factor in AWD

\begin{tabular}{|l|l|l|l|}
\hline Chi square statistic & p value & Odds ratio & $95 \%$ CI \\
\hline 8.799 & $\mathbf{0 . 0 0 3 0}$ & $\mathbf{4 . 5 7 1}$ & $\mathbf{1 . 7 0 5}$ to $\mathbf{1 2 . 2 5 4}$ \\
\hline Degree of freedom $=1$ &
\end{tabular}

$\mathrm{p}$ value obtained is considered statistically significant.

\section{Electrolytes}


Table 12: Sodium

\begin{tabular}{|l|l|l|}
\hline Variable & Cases & Controls \\
\hline hyponatremia & $12(40.0 \%)$ & $40(44.4 \%)$ \\
\hline Normal & $18(60.0 \%)$ & $50(55.6 \%)$ \\
\hline
\end{tabular}

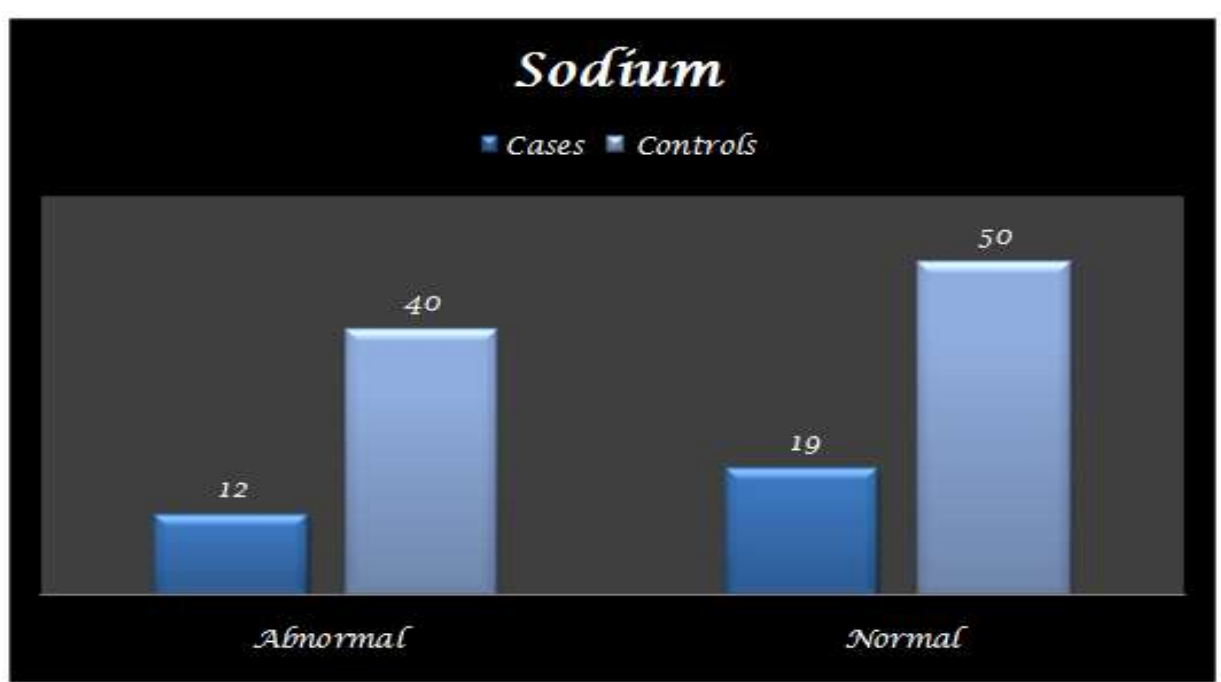

Fig 9: Graph showing the hyponatremia as risk factor in AWD

\begin{tabular}{|l|l|l|l|}
\hline Chi square statistic & p value & Odds ratio & $95 \%$ CI \\
\hline 0.04525 & $\mathbf{0 . 8 3 1 5}$ & $\mathbf{0 . 8 3 3 3}$ & $\mathbf{0 . 3 5 9 5}$ to 1.932 \\
\hline Degree of freedom $=1$ & \multicolumn{3}{|l}{} \\
\hline
\end{tabular}

Table 13: Potassium

\begin{tabular}{|l|l|l|}
\hline Variable & Cases & Controls \\
\hline Hypokalemia & $22(73.3 \%)$ & $44(48.9 \%)$ \\
\hline Normal & $8(26.7 \%)$ & $46(51.1 \%)$ \\
\hline
\end{tabular}

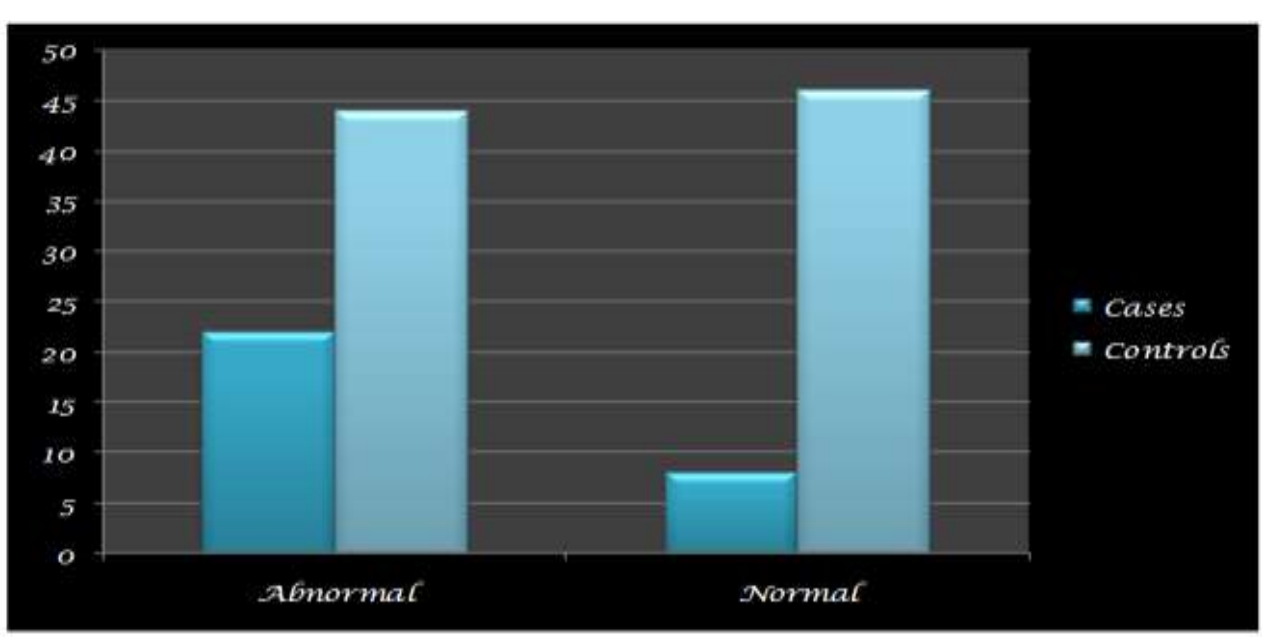

Fig 10: Graph showing the hypokalemia as risk factor in AWD

\begin{tabular}{|l|l|l|l|}
\hline Chi square statistic & $\mathrm{p}$ value & Odds ratio & 95\% CI \\
\hline 4.489 & $\mathbf{0 . 0 3 4 1}$ & $\mathbf{2 . 8 7 5}$ & $\mathbf{1 . 1 5 9}$ to 7.134 \\
\hline Degree of freedom $=1$
\end{tabular}

Obtained $\mathrm{p}$ value is considered statistically significant

Table 14: Malignancy

\begin{tabular}{|l|l|l|}
\hline Variable & Cases & Controls \\
\hline Malignant & $10(33.3 \%)$ & $8(8.9 \%)$ \\
\hline Non malignant & $20(66.7 \%)$ & $82(91.1 \%)$ \\
\hline
\end{tabular}




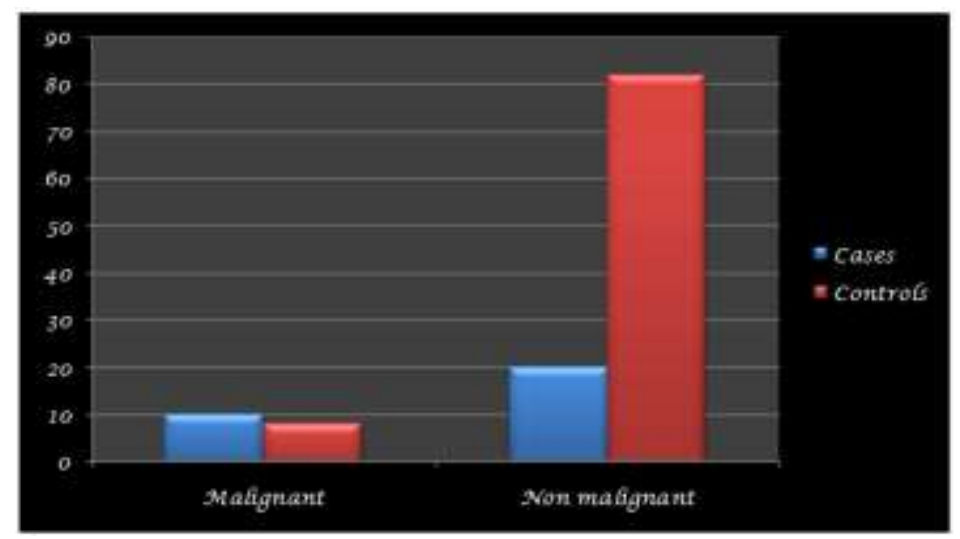

Fig 11: Impact of malignancy in AWD

\begin{tabular}{|l|l|l|l|}
\hline Chi square statistic & p value & Odds ratio & 95\% CI \\
\hline 8.715 & $\mathbf{0 . 0 0 3 2}$ & $\mathbf{5 . 1 2 5}$ & $\mathbf{1 . 7 9 2}$ to 14.654 \\
\hline Degree of freedom $=1$ & \multicolumn{4}{|l|}{} \\
\hline
\end{tabular}

Obtained $\mathrm{p}$ value is considered to be statistically significant. Odds ratio shows positive association.

Table 15: Diabetes

\begin{tabular}{|l|l|l|}
\hline Variable & Cases & Controls \\
\hline Diabetic & $10(33.3 \%)$ & $6(6.7 \%)$ \\
\hline Non-diabetic & $20(66.7 \%)$ & $84(93.3 \%)$ \\
\hline
\end{tabular}

Diabetes mellitus has been said to have effect on all stages of wound healing. It causes atherosclerosis of the vessels and leads to tissue hypoxia. Diabetics are further more susceptible to infections because of decreased inflammatory response and inefficient bacterial killing. There will also be the impairment in the collagen synthesis in diabetes. All these factors leads to bursting of the abdomen.

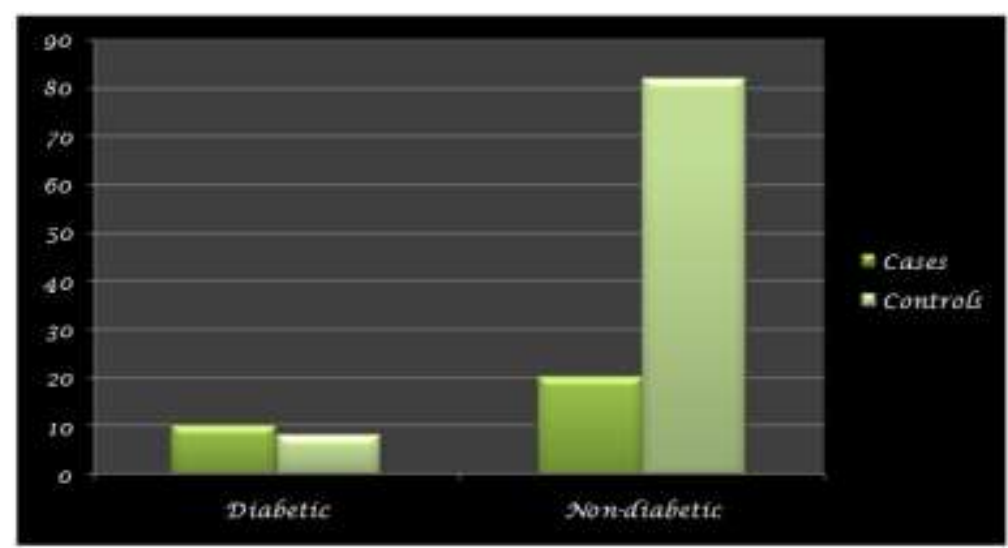

Fig 12: Impact of diabetes on AWD

\begin{tabular}{|l|l|l|l|}
\hline Chi square statistic & $\mathrm{p}$ value & Odds ratio & 95\% CI \\
\hline 11.635 & $\mathbf{0 . 0 0 0 6}$ & $\mathbf{7 . 0 0 0}$ & $\mathbf{2 . 2 7 5}$ to 21.535 \\
\hline Degree of freedom $=1$ &
\end{tabular}

$\mathrm{p}$ value obtained seems significant and odds ratio shows positive association.

Table 16: Elective Vs Emergency Procedures

\begin{tabular}{|l|l|l|}
\hline Variable & Cases & Controls \\
\hline Emergency & $25(83.3 \%)$ & $70(77.8 \%)$ \\
\hline Elective & $5(16.7 \%)$ & $20(22.2(\%)$ \\
\hline
\end{tabular}

Emergency surgery is considered as a risk factor for the development of abdominal wound dehiscence since many factors contributes to this, such as presence of intra-abdominal sepsis, presence of uremia, presence of renal failure, presence of malnourishment, anemia, requirement of intestinal stomas, increased intraabdominal tension, suboptimal management of the abdominal layers, greater risk of surgical field contamination, improper maintenance of sterility etc. All these mentioned factors were found to be less in elective procedures. So, less risk of dehiscence. 


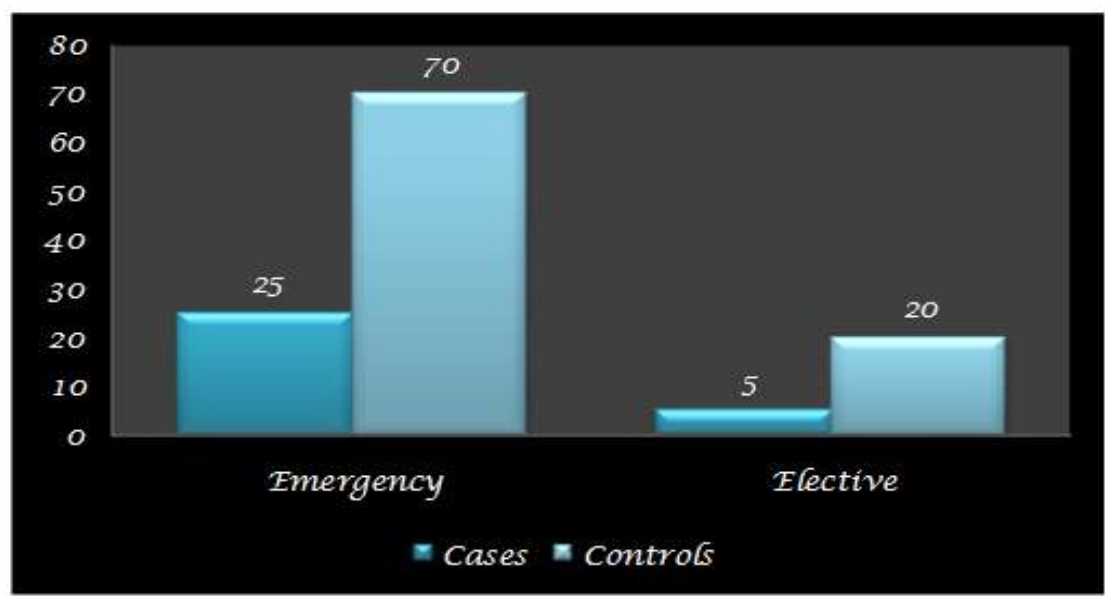

Fig 13: Elective/emergency procedures as risk factor in AWD

\begin{tabular}{|l|l|l|l|}
\hline Chi square statistic & $p$ value & Odds ratio & $95 \%$ CI \\
\hline 0.1516 & $\mathbf{0 . 6 9 7 0}$ & $\mathbf{1 . 4 2 9}$ & $\mathbf{0 . 4 8 4 4}$ to 4.213 \\
\hline Degree of freedom $=1$ & \multicolumn{3}{|l}{} \\
\hline
\end{tabular}

The $\mathrm{p}$ value obtained from our data seems insignificant but the odds ratio obtained is $>1$, which can be interpreted that there is positive association of emergency procedures and dehiscence.

Table 17: Contamination

\begin{tabular}{|l|l|l|}
\hline Variable & Cases & Controls \\
\hline Abnormal & $23(76.7 \%)$ & $39(43.3 \%)$ \\
\hline Normal & $7(23.3 \%)$ & $51(56.7 \%)$ \\
\hline
\end{tabular}

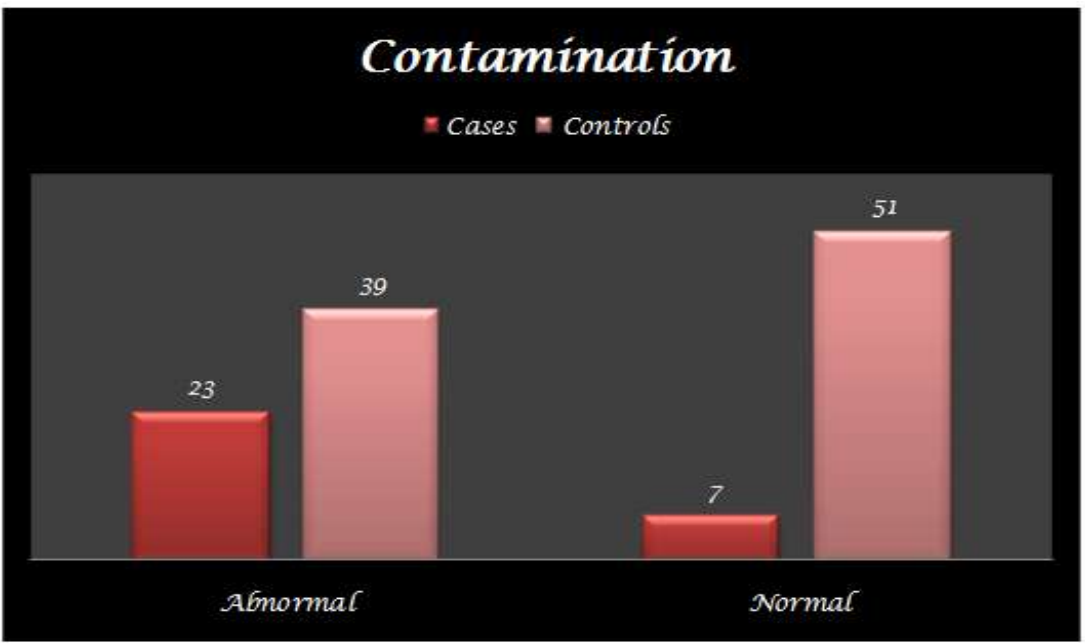

Fig 14: Presence of contamination as risk factor in AWD

\begin{tabular}{|l|l|l|l|}
\hline Chi square statistic & p value & Odds ratio & $95 \%$ CI \\
\hline 8.721 & $\mathbf{0 . 0 0 3 1}$ & $\mathbf{4 . 2 9 7}$ & $\mathbf{1 . 6 7 3}$ to $\mathbf{1 1 . 0 3 7}$ \\
\hline Degree of freedom $=1$ & \\
\hline
\end{tabular}

Obtained p value shows statistical significance. Odds ratio also shows positive association between the contamination, so called risk factor and development of burst abdomen.

Table 18: Stoma

\begin{tabular}{|l|l|l|}
\hline Variable & Cases & Controls \\
\hline Stoma present & $10(33.3 \%)$ & $8(8.9 \%)$ \\
\hline Stoma absent & $20(66.7 \%)$ & $82(91.1 \%)$ \\
\hline
\end{tabular}

Most of the lower gastrointestinal cases which were presented in emergency conditions have been operated with the placement of intestinal stomas. The presence of a stoma in the post-operative period has been demonstrated to play a significant role in the development of wound infections, further leading to delayed healing process. 


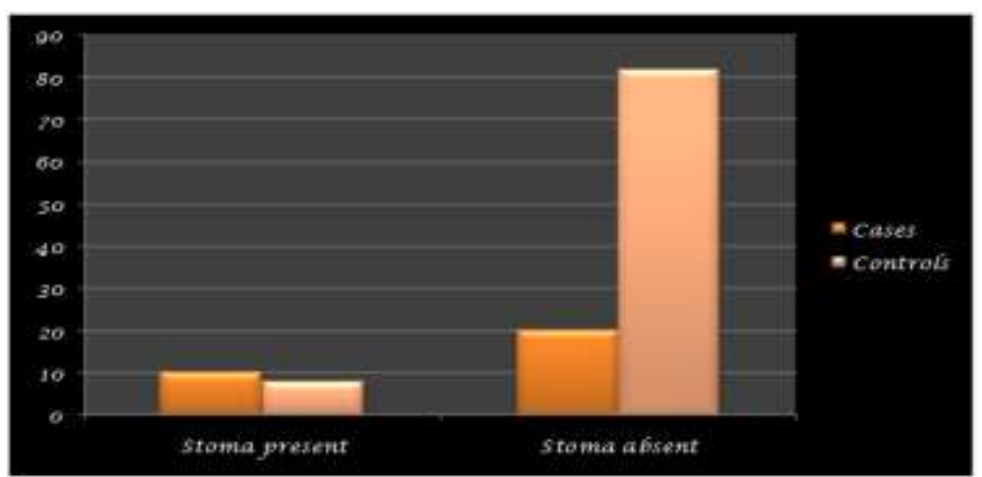

Fig 15: Risk of presence of stoma

\begin{tabular}{|l|l|l|l|}
\hline Chi square statistic & $\mathrm{p}$ value & Odds ratio & 95\% CI \\
\hline 8.715 & $\mathbf{0 . 0 0 3 2}$ & $\mathbf{5 . 1 2 5}$ & $\mathbf{1 . 7 9 2}$ to $\mathbf{1 4 . 6 5 4}$ \\
\hline Degree of freedom $=1$ & \multicolumn{3}{|l}{} \\
\hline
\end{tabular}

$\mathrm{p}$ value is considered as statistically significant.

Table 19: Tension sutures

\begin{tabular}{|l|l|l|}
\hline Variable & Cases & Controls \\
\hline Tension sutures present & $8(26.7 \%)$ & $25(27.8 \%)$ \\
\hline Tension sutures absent & $22(73.3 \%)$ & $65(72.2 \%)$ \\
\hline
\end{tabular}

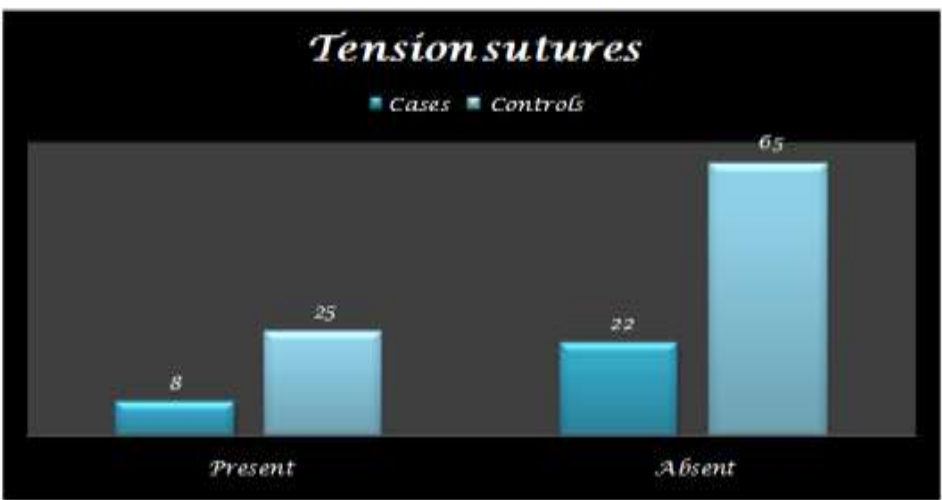

Fig 16: Presence of tension sutures-protective factor in AWD

\begin{tabular}{|l|l|l|l|}
\hline Chi square statistic & $\mathrm{p}$ value & Odds ratio & $95 \%$ CI \\
\hline 0.01393 & $\mathbf{0 . 9 0 6 0}$ & $\mathbf{0 . 9 4 5 5}$ & $\mathbf{0 . 3 7 2 4}$ to 2.400 \\
\hline Degree of freedom $=1$ & \multicolumn{3}{|l}{} \\
\hline
\end{tabular}

Table 20: Cough (Elevated intra-abdominal pressure)

\begin{tabular}{|l|l|l|}
\hline Variable & Cases & Controls \\
\hline Cough present & $13(43.3 \%)$ & $10(11.1 \%)$ \\
\hline No cough & $17(56.7 \%)$ & $80(88.9 \%)$ \\
\hline
\end{tabular}

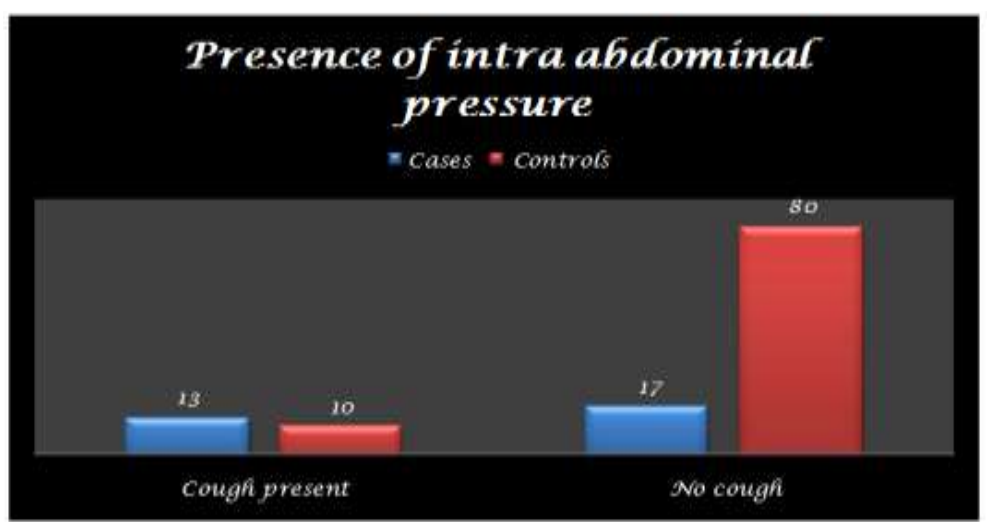

Fig 17: Risk of raise in IAP on AWD 
A Nested Case Control Study Of The Abdominal Wound Dehiscence In A Rural Hospital In South...

\begin{tabular}{|l|l|l|l|}
\hline Chi square statistic & $\mathrm{p}$ value & Odds ratio & $95 \%$ CI \\
\hline 13.070 & $\mathbf{0 . 0 0 0 3}$ & $\mathbf{6 . 1 1 8}$ & $\mathbf{2 . 3 0 3}$ to $\mathbf{1 6 . 2 4 8}$ \\
\hline Degree of freedom $=1$ \\
\hline
\end{tabular}

Obtained p-value is considered as statistically significant.

Table 21: Smoking/Tobacco

\begin{tabular}{|l|l|l|}
\hline Variable & Cases & Controls \\
\hline Exposed & $15(50.0 \%)$ & $21(23.3 \%)$ \\
\hline Unexposed & $15(50.0 \%)$ & $69(76.7 \%)$ \\
\hline
\end{tabular}

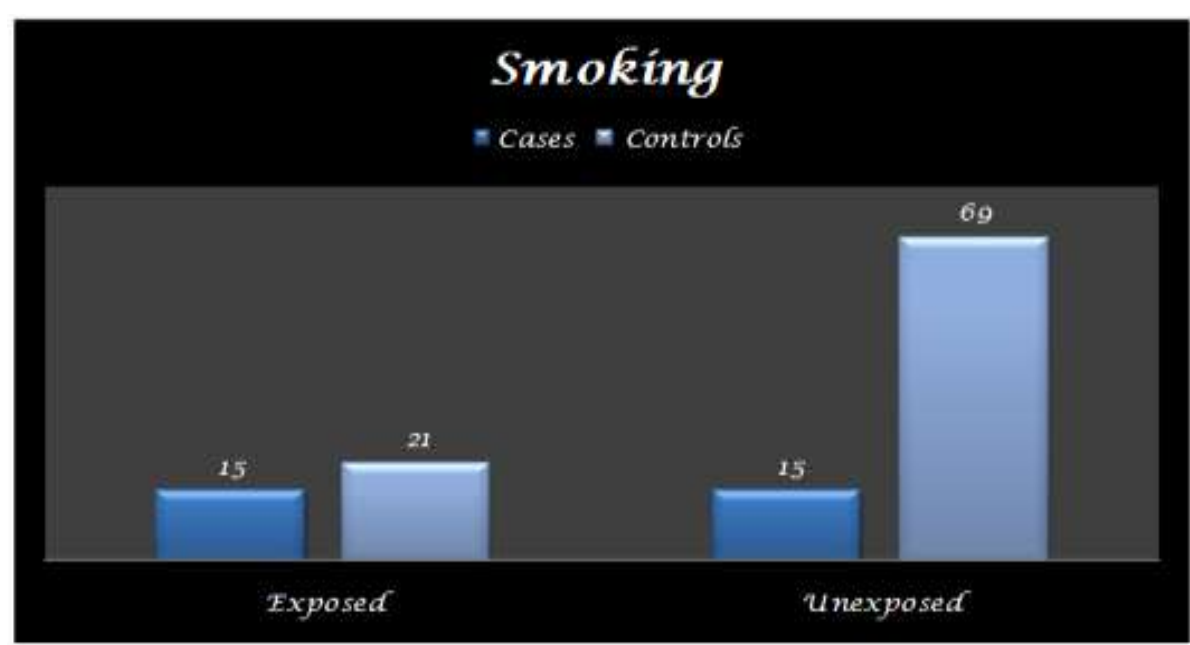

Fig 18: Impact of smoking on AWD

\begin{tabular}{|l|l|l|l|}
\hline Chi square statistic & $\mathrm{p}$ value & Odds ratio & $95 \%$ CI \\
\hline 6.042 & $\mathbf{0 . 0 1 1 4}$ & $\mathbf{3 . 2 8 6}$ & $\mathbf{1 . 3 8 1}$ to $\mathbf{7 . 8 1}$ \\
\hline Degree of freedom $=1$ & \multicolumn{3}{|l}{} \\
\hline
\end{tabular}

$\mathrm{p}$ value obtained is statistically significant and the odds ratio shows positive association between the risk factor and dehiscence.

Table 22: Alcohol

\begin{tabular}{|l|l|l|}
\hline Variable & Cases & Controls \\
\hline Alcoholics & $10(33.3 \%)$ & $21(23.3 \%)$ \\
\hline Non-alcoholics & $20(66.7 \%)$ & $69(76.7 \%)$ \\
\hline
\end{tabular}

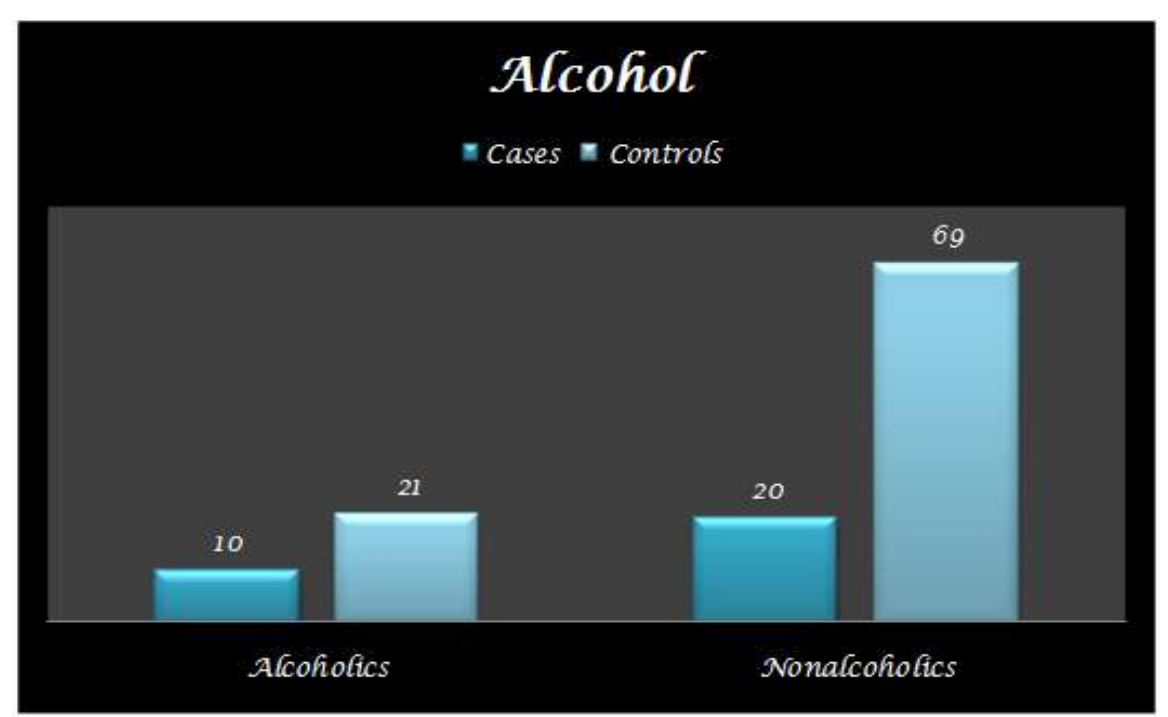

Fig 19: Impact of alcohol on AWD

\begin{tabular}{|l|l|l|l|}
\hline Chi square statistic & p value & Odds ratio & $95 \%$ CI \\
\hline 0.7104 & $\mathbf{0 . 3 9 9 3}$ & $\mathbf{1 . 6 4 3}$ & $\mathbf{0 . 6 6 6 0}$ to $\mathbf{4 . 0 5 2}$ \\
\hline Degree of freedom $=1$ & \\
\hline
\end{tabular}


Day of Dehiscence

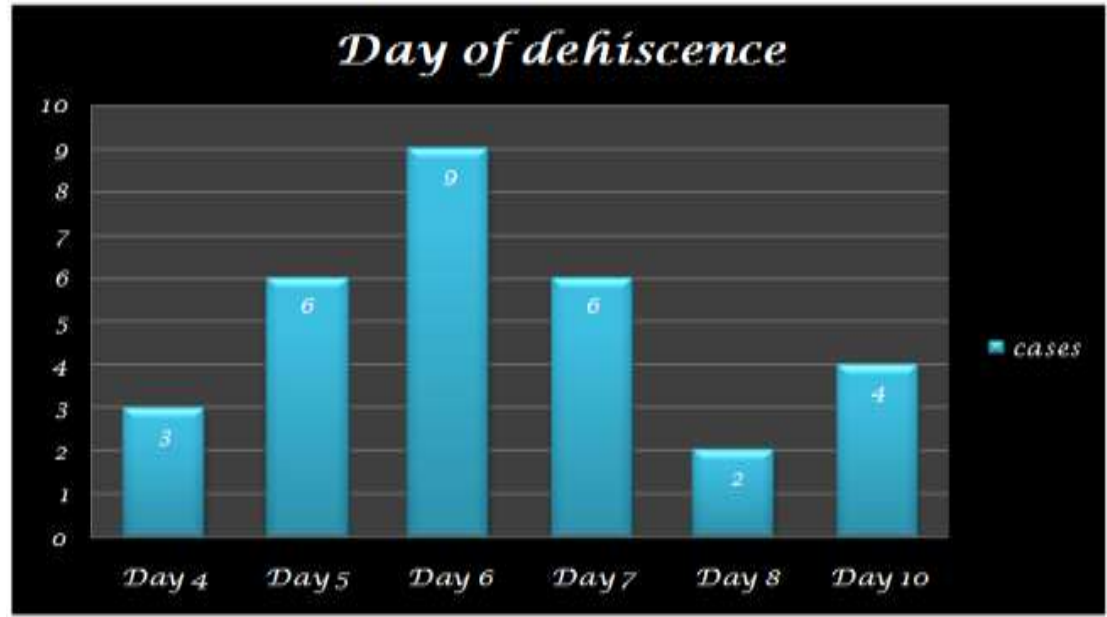

Fig 20: Graph showing the day of dehiscence

From the available data, most of the cases developed dehiscence by day 6; the calculated mean value for day of dehiscence is 6.46days.

\section{Wound infection}

The most common cause of delay in wound healing is the presence of infection. Presence of bacteria prolongs the inflammatory phase and interferes with the epithelialisation, wound contraction and collagen deposition.

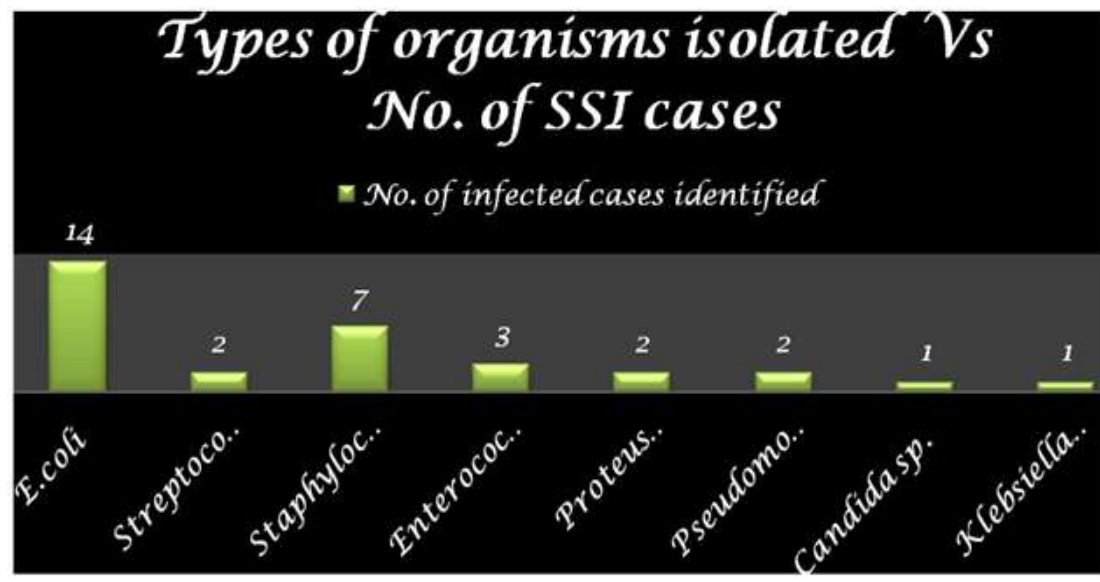

Fig 21: Graph showing the type of organisms isolated

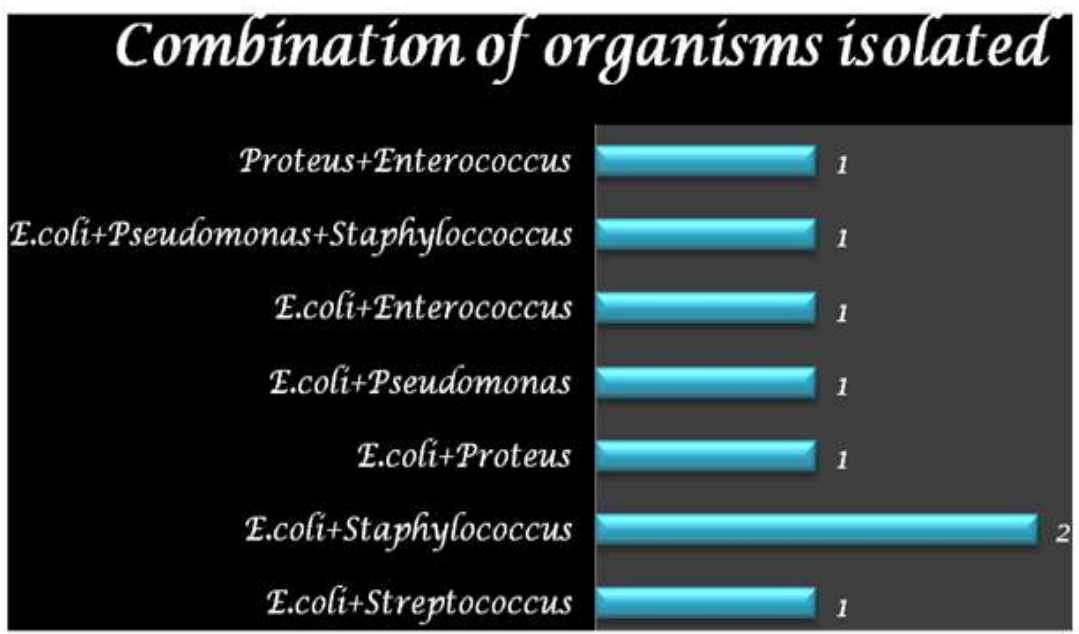

Fig 22: Graph showing the combination of organisms isolated 


\section{Discussion}

Abdominal wound dehiscence is still a significant cause of morbidity after major abdominal operations with incidence ranging from $0.4 \%$ to $3.5 \%{ }^{76}$. The incidence for Abdominal Wound Dehiscence was found to be $6 \%$ in our hospital. There are various reasons for this higher incidence. The cause of the tearing may be secondary, to both patient and surgeon related factors. The precise contribution of any one factor toward increasing the dehiscence risk is difficult to know, but certainly a patient with many putative risk factors is at a higher risk than a patient with none. Even though the surgeon has no control over patient related factors like advanced age, male sex, malignancy etc which increase the risk of wound disruption, but still surgeon can play a major role in prevention of this complication. Majority of the cases operated in our hospital were presented in emergency. The delay in presentation to the hospital also effects the outcome of the patient in terms of the presence of septic shock and infective foci. The more the delay in presentation the worse is the outcome. Hence we ascertain the delayed presentation of the patients to the hospital in emergency situation as one of the important cause for the increased incidence rate of abdominal wound dehiscence in our hospital. Coming to individual risk factors, odds ratio, $95 \%$ confidence interval and $\mathrm{p}$ value are calculated for each and every risk factor. Most of the values are significant. Since the sample size is very small, some insignificant values are also obtained.

Advanced age is identified as a risk factor in wound disruption in a study conducted by Riou JP et al $(1992)^{67}$. According to the study by Lenhardt R. et al $(2000)^{79}$, collagen deposition after surgery decreases significantly with advancing age. Younger men and women deposited similar amounts of collagen. In our study, we found higher incidence of abdominal wound dehiscence in age group of 40-60years, with mean age of 41.2 years.

Obesity is said to be the risk factor for abdominal wound dehiscence. The presence of excessive adipose tissue in the subcutaneous layers makes obliteration of the dead space more difficult and because of increased difficulties with hemostasis encompass the formation of hematoma and would infection. ${ }^{80}$ Similarly it is proved to be one of the risk factor for AWD ( $p<0.05)$. The OR (7.269) and 95\% CI (1.847 to 28.605) also shows positive association between obesity and AWD. 10 out of 30 patients were overweight in our study. These results are similar to those with the study conducted by Israelsson LA et al(1997), concluded that overweight is an independent risk factor for the development of wound dehiscence

In a study conducted by Arunabha Sinha et al(2015) out of 57 patients about $43.8 \%$ of patients showed hemoglobin $<10 \mathrm{gm} \%$. The effect of anaemia on wound healing often is compounded by the associated hypovolemia or hypoxia. anaemia and hypovolemia cause decreased tissue oxygenation causing impairment of wound healing by decrease in wound tensile strength. In our study, anemia $(\mathrm{p}<0.05)$ was found to be significant risk factor. OR (2.983), 95\% CI (1.265 to 7.034) also shows the positive association among anemia, the so called risk factor and burst abdomen.

Serum albumin plays a key role in process of wound healing as discussed above in results. Hypoalbuminaemia $(\mathrm{p}<0.05)$ is also considered as one of the risk factor for development of dehiscence. OR (3.143) and 95\% CI (1.335 to 7.399) values show the positive association between hypoalbuminaemia and AWD. In a study carried out at Oula University Hospital ${ }^{81}$, among 48 patients who developed wound dehiscence, there were $31(65 \%)$ patients with pre-operative hypoalbuminemia, other risk factors included anemia, malnutrition, chronic lung disease and emergency procedure. Hypoproteinemia $(\mathrm{p}<0.05)$ is also considered as one of the significant risk factor in our study. Positive association was found between hypoproteinemia and burst abdomen with OR (3.667) and 95\% CI(1.508 to 8.917).

There is remarkably little objective clinical evidence regarding the effect of uremia on wound healing although the clinical impressions of experimental surgeons have suggested that it does affect wound repair. However, hyperalimentation properly adjusted for the renal failure patient may counter the putative defect of healing associated with uremia ${ }^{24}$.

In our study uraemia is also found to be a significant risk factor $(\mathrm{p}<0.05)$. Positive association is seen between uremia and AWD with OR (2.813) and 95\% CI (1.202 to 6.582). similar results were observed in a clinical study conducted by M.Khan et al $(2004)^{85}$ and a.Aziz et al $(2009)^{86}$. Renal failure can be predicted by higher levels of serum creatinine. Patients with higher levels of serum creatinine developed AWD $(\mathrm{p}<0.05)$ OR (2.591) and 95\% CI (1.103 to 6.087) also shows positive significant association between the mentioned risk factor renal failure and AWD.

Serum lactate is said to be one among the list of risk factors of AWD by many authors. Obtained $\mathrm{p}$ value $(\mathrm{p}<0.05)$ OR $(4.571) 95 \%$ CI $(1.705$ to 12.254$)$ shows that serum lactate is significant independent risk factor for abdominal wound dehiscence.

Hyponatremia is considered as an independent risk factor for AWD. But unfortunately, in our study we got an insignificant value ( $\mathrm{p}>0.05)$. Also the OR and 95\% CI reveal negative association. However, hypokalemia was considered as significant risk factor ( $\mathrm{p}<0.05)$, OR (2.875) and 95\% CI (1.159 to 7.134).In the study done by Riou JP et al (1992) ${ }^{67}$ identified malignancy as a risk factor in wound disruptions. Malignancy 
per se might not predispose to wound disruption but associated general debility and hypoproteinemia certainly cause increase in the incidence.In our study, 10 out of 30 cases were having a malignant disease. Malignancy is an independent risk factor for the development of abdominal dehiscence with a strong positive association $(\mathrm{p}<0.05)$ OR (5.125) 95\% CI (1.792 to 14.654)

Diabetes has significant impact on all stages of wound healing. Moreover, diabetics are furthermore susceptible to infections. Diabetes is often associated with poor wound healing. Granulocytes from diabetic patients demonstrate decreased phagocytic activity and poor chemotaxis. These granulocyte defects and local ischemia secondary to accelerated atherosclerosis and small vessel disease result in increased susceptibility to infection $^{58}$. This may increase the risk of developing dehiscence. In our study, diabetes is considered as one of the significant risk factor ( $\mathrm{p}<0.05)$, also OR (7.000) and 95\% CI $(2.275$ to 21.535). This result is compared with the similar results obtained in a study carried out by Pradeep soni et al (2015) in Chattisgarh institute of medical sciences, Bilaspur, India ${ }^{84}$.

Emergency surgical procedures have higher risk of dehiscence than elective procedures. As the patients undergoing surgery in emergency are in suboptimal condition, hemodynamically unstable, and the risk of contamination of surgical field is high. The concert of the surgeon can be affected leading to the inappropriate closure of the abdomen at the end of surgical procedure. The results in our study are similar to the study conducted by Pradeep soni et al $(2015)^{84}$. But unfortunately, we found it insignificant $(\mathrm{p}<0.05)$. But OR (1.429) suggests positive association i.e., there is risk of development of burst abdomen having emergency procedure as risk factor when compared with the elective procedures.

Contamination is also considered as one of the significant risk factor in AWD ( $\mathrm{p}<0.05)$ OR (4.297) and $95 \%$ CI (1.673 to 11.037). In a prospective clinical study by T.T. Irvin et al (1977) ${ }^{77}$ showed wound infection is associated with a tenfold increase in the incidence of wound disruption. The incidence of postoperative wound infection can be reduced by usage of prophylactic antimicrobials. In established cases of wound infection, pus should be drained and appropriate antibiotics to be started based on culture sensitivity reports. In our study most of the surgical site infections grown E.coli on the cultural medium.

Tension sutures acts as protective factor from preventing the dehiscence. In a study conducted by Khorgami $\mathrm{Z}$ et al(2013) prophylactic retention sutures reduce the occurrence of WD following midline laparotomy in high-risk patients with multiple risk factors for impaired wound healing without imposing remarkable postoperative complications ${ }^{82}$. But in our study we got statistical insignificance for this $(\mathrm{p}<0.05)$. OR (0.945) suggests negative association i.e., the application of tension sutures offers no protection from the development of wound dehiscence.

The triad of abdominal distention, vomiting and cough increase the intra abdominal pressure and wound disruption $^{67}$. It was found to be statistically significant in our study (p<0.05) OR (6.11) 95\% CI $(2.303$ to 16.248). 13 patients in this study had post operative cough which is a risk factor for causing increasing intra abdominal pressure and further leading to wound disruption. Chest physiotherapy, tracheobronchial toilet will reduce the frequency of wound failure. Therefore post operative cough is considered as an independent risk factor.

The day of wound dehiscence ranges from $4^{\text {th }}$ postoperative day to $12^{\text {th }}$ postoperative day and average of 6.9 days. Keill et al $(1973)^{78}$ reported similar findings, with average postoperative day of dehiscence of 7 days.

\section{Conclusion}

Wound dehiscence is a complication that haunts every abdominal surgeon. The incidence of abdominal wound dehiscence ranges from $0-3 \%$. Numerous risk factors, including the patient related and surgeon related risk factors were known to cause abdominal wound dehiscence.

In our teaching hospital which is a Secondary level hospital in a rural area, an overall incidence of $6 \%$ of abdominal wound dehiscence is observed in comparison to others.

In this study, many risk factors were observed to be the cause for the development of abdominal wound dehiscence. Majority of the cases operated in our hospital were presented in emergency. The delay in presentation to the hospital also effects the outcome of the patient in terms of the presence of septic shock and infective foci. The more the delay in presentation the worse is the outcome. Hence we ascertain the delayed presentation of the patients to the hospital in emergency situation as one of the important causes for the increased incidence rate of abdominal wound dehiscence in our hospital.

Many of the patient related risk factors were proved to be the cause for the development of dehiscence. Hypoproteinemia, Anaemia, Renal failure, uremia, presence of malignancy, associated diseases like Diabetes, hypertension, COPD and immunocomprimised state of the patient, factors which increase intra abdominal pressure like post operative cough, vomiting, abdominal distension and urine retention, development of the wound infection plays a role in the development of wound dehiscence. 
Surgeons can aim to reduce the development of abdominal wound dehiscence by

1. Prevention of surgical site infections by using appropriate antimicrobial prophylaxis and during the post operative period.

2. Improving the nutritional status of the patients by providing high protein diet and maintain the hemoglobin in near normal limits.

3. Prevention of the development of increased abdominal tension by suppressing the cough, avoiding hiccups, to avoid urinary retention by continuous drainage of the bladder.

4. Maintaining proper antiseptic precautions while handling the patient in the wards while changing the dressings and during surgical procedures.

5. Employing good surgical techniques during the closure of the abdominal wounds by taking equal and adequate thickness of the rectus sheath on either sides of the surgical wound.

6. Proper peritoneal toileting with warm saline before the abdominal closure particularly in contaminated and dirty cases.

7. Providing tension sutures to the patient is of doubtful benefit in preventing the development of wound dehiscence. Hence we advice careful patient selection for the application of retention sutures.

\section{References}

[1]. Fleischer GM, Rennert A, Ruhmer M. [Infected abdominal wall and burst abdomen]. Chirurg. GERMANY; 2000 Jul;71(7):754-62

[2]. Carlson MA. Acute wound failure. Surg Clin North Am. UNITED STATES; 1997 Jun;77(3):607-36.

[3]. Skandalakis J, Colborn G. Skandalakis' Surgical anatomy. Athens, Greece: PMP; 2004. Page

[4]. Sabiston Textbook of Surgery-The Biological Basis of Modern Surgical Practice, $19^{\text {th }}$ edition, Elsevier Saunders, 2012 page 1096

[5]. Brunicardi F, Schwartz S. Schwartz's principles of surgery. New York: McGraw-Hill, Health Pub. Division; 2005.Page 1449

[6]. Standring S, editor. Gray's anatomy: the anatomical basis of clinical practice. 39th ed. Edinburgh: Elsevier; 2005. Page 2581-2596

[7]. Williams N, Bulstrode C, O'Connell P, Bailey H, Love R. Bailey \& Love's short practice of surgery. London: Hodder Arnold; 2008. Page 948

[8]. Standring S, editor. Gray's anatomy: the anatomical basis of clinical practice. 40th ed. Edinburgh: Elsevier; 2008. Page 1054-1067

[9]. Brantigan OC. Clinical Anatomy. Newyork : Mcgraw-Hill,1963

[10]. R M H Mc minn. Last's Anatomy Regional and Applied 9th Ed: Churchill Livingstone : 1995.

[11]. Guillou PJ, Hall TJ, Donaldson DR, Broughton AC, Brennan TG. Vertical abdominal incisions--a choice? Br J Surg. ENGLAND; 1980 Jun;67(6):395-9.

[12]. McBurney C. IV. The Incision Made in the Abdominal Wall in Cases of Appendicitis, with a Description of a New Method of Operating. Ann Surg. United States; 1894 Jul;20(1):38-43.

[13]. Shackelford R, Zuidema G, Orringer M, Ritchie W, Turcotte J, Condon R et al. Shackelford's surgery of the alimentary tract. Philadelphia, Pa.: W.B. Saunders; 1996. Page 556-626

[14]. Maingot R, Zinner M, Ashley S. Maingot's abdominal operations. New York: McGraw-Hill Medical; $2007 . P a g e ~ 385$.

[15]. Jenkins TPN : The bust abdominal wound : A mechanical appraoch. Br. J.Surg 1976; 63:873.

[16]. Ellis H, Heddle R. Does the peritoneum need to be closed at laparotomy? Br J Surg. ENGLAND; 1977 Oct;64(10):733-6

[17]. Tulandi T, Al-Jaroudi D. Nonclosure of peritoneum: a reappraisal. Am J Obstet Gynecol. United States; 2003 Aug;189(2):609-12.

[18]. Wadstrom J, Gerdin B. Closure of the abdominal wall; how and why? Clinical review. Acta Chir Scand. SWEDEN; 1990 Jan; 156(1):75-82.

[19]. Goligher JC, Irvin TT, Johnston D, De Dombal FT, Hill GL, Horrocks JC. A controlled clinical trial of three methods of closure of laparotomy wounds. Br J Surg. ENGLAND; 1975 Oct;62(10):823-9.

[20]. Bucknall TE, Ellis H. Abdominal wound closure--a comparison of monofilament nylon and polyglycolic acid. Surgery. UNITED STATES; 1981 Jun;89(6):672-7.

[21]. Leaper DJ, Pollock A V, Evans M. Abdominal wound closure: a trial of nylon, polyglycolic acid and steel sutures. Br J Surg. ENGLAND; 1977 Aug;64(8):603-6.

[22]. Mangram AJ, Horan TC, Pearson ML, Silver LC, Jarvis WR. Guideline for Prevention of Surgical Site Infection, 1999. Centers for Disease Control and Prevention (CDC) Hospital Infection Control Practices Advisory Committee. Am J Infect Control [Internet]. 1999;27(2):97-132; quiz 133-4; discussion 96. Available from: http://www.ncbi.nlm.nih.gov/pubmed/10196487

[23]. Ranaboldo CJ, Rowe-Jones DC. Closure of laparotomy wounds: skin staples versus sutures. Br J Surg. ENGLAND; 1992 Nov;79(11):1172-3.

[24]. Carlson MA. Acute wound failure. Surg Clin North Am. 1997; 77:607-36.

[25]. Last's Anatomys Regional and Applied 9th Ed : 1995.:

[26]. Efron G: Abdominal wound disruption. Lancet 1965; 1:1287-91.

[27]. Invin T.T. et al : Layer closure of laprotomy wounds with absorbable and non absorbable suture materials. Br. J Surg 1976; 63: 79396.

[28]. P.J. Guillon et al : Vertical abdominal incisions - a choice ? Br J Surg 1980; 67:395-99.

[29]. Hampton JR : The Burst abdomen. Br.Med J 1963; 2:1032/

[30]. Richards PC et al: Abdominal wound closure. A randomised prospective study of 571 patients comparing continous Vs interrupted suture techniques. Ann surg 1983; 197:238.

[31]. Bucknall TE et al : Burst abdomen and incisional Hernia. A prospective study of 1129 major laprotomies Br Med 1982; 284:93133.

[32]. Greenall MJ et al : Midline or transverse laprotomy ? A random controlled clinical trial. Part I. Influence on healing. Br. J Surg 1980; 67:188-90/

[33]. Goligher JC et al : A controlled clinical trial of three methods of closure of laprotomy wounds. Br J Surg 1975; 62:823.

[34]. Dennis E.Weiland et al : Choosing the best abdominal closure by Meta-Analysis Am. J.Surg. 1998; 176:666-70

[35]. Knight $\mathrm{CD}$ et al : Abdominal wound closure with a continous monofilament polypropylene suture. Experience with 1000 consecutive cases. Arch Surg 1983; 118:1305-8.

[36]. Isralesson et al : Closure of midline laprotomy incisions with polydioxaonae and nylon : the importance of suture technique. Br. $\mathrm{J}$ Surg. 1994; 81:1606-8 
[37]. Carlson et al. polyglyconate (Maxon) versus nylon suture in midline abdominal incision closure : a prospective randomised trail. Am Surg 1995; 61:980-83.

[38]. Hugh TB et al : Is closure of the periotoneal layer necessary in the repair of midline surgical abdominal wounds. World J Surg. $1990 ; 14: 231-33$.

[39]. Duffy et al. Is peritoneal closure necessary ? Obstet Gynecol Surv 1994; 49:817-22.

[40]. Madsen et al. Burst abdomen : Clinical features and factors influencing mortality. Dan Med Bull 1992; $39: 183$.

[41]. Dudley HA Layered and mass closure of the abdominal wall; a theoretical and experimental analysis. Br J Surg 1970; 57:664-67.

[42]. Banerjee $\mathrm{P}$ et al. Critical evaluation of conventional abdominal closure with single-layer closure in adult and elderly. J Indian Med Assoc. 1989; 87:277-78

[43]. Chaudhary SK et al. Mass closure versus layer closure of abdominal wound : a prospective clinical study. J Indian Med Assoc. 1994; 92:229-32.

[44]. Fagniez et al. Abdominal midline incision closure. A multicentric randomized prospective trial of 3,135 patients, comparing continous Vs interrupted polyglycolic acid and sutures. Arch Surg 1985; 120:11351-53.

[45]. Trimbos JB et al. A randomized clinical trial comparing two methods of fascia closure following midline laprotomy. Arch Surg 1992; 127:1232.

[46]. Leaper DJ. Angiography as an index of healing in experimental laprotomy wounds and colonic anastomoses. Ann R Coll Surg. Engl. 1983; 65:20.

[47]. Tera $\mathrm{H}$ et al. Strength of knots in surgery in relation to type of knot, type of suture material and dimension of suture threach. Acta Chir Scand 1977, 143:75.

[48]. Carlson MA. Acute wound failure. Surg Clin North Am. 1997; 77:607-36.

[49]. Swift ME, Burns AL, Gray KL, DiPietro LA. Age-related alterations in the inflammatory response to dermal injury. J Invest Dermatol. United States; 2001 Nov;117(5):1027-35.

[50]. Gosain A, DiPietro LA. Aging and wound healing. World J Surg. United States; 2004 Mar;28(3):321-6.

[51]. Anaya DA, Dellinger EP. The obese surgical patient: a susceptible host for infection. Surg Infect (Larchmt). United States; 2006 Oct:7(5):473-80.

[52]. Greco JA 3rd, Castaldo ET, Nanney LB, Wendel JJ, Summitt JB, Kelly KJ, et al. The effect of weight loss surgery and body mass index on wound complications after abdominal contouring operations. Ann Plast Surg. United States; 2008 Sep;61(3):235-42.

[53]. Wilson JA, Clark JJ. Obesity: impediment to postsurgical wound healing. Adv Skin Wound Care. United States; 2004 Oct;17(8):426-35.

[54]. Rodriguez PG, Felix FN, Woodley DT, Shim EK. The role of oxygen in wound healing: a review of the literature. Dermatol Surg. United States; 2008 Sep;34(9):1159-69.

[55]. MATHIEU D, LINKE JC, WATTEL F: Non-healing wounds. In: Handbook on Hyperbaric Medicine. D. MATHIEU (ed), Springer, Netherlands, 2006, pp 401-427

[56]. Waldron DR, Zimmerman-Pope N. Superficial skin wounds. In: Textbook of small animal surgery. Slatter DH, editor. , editor. NY: Saunders, 2003, pp 260-271

[57]. Campos ACL, Groth AK, Branco AB. Assessment and nutritional aspects of wound healing. Curr Opin Clin Nutr Metab Care. England; 2008 May; 11(3):281-8.

[58]. John H Davis - A problem solving approach, Vol 12nd Ed : 1995.

[59]. Franz MG, Steed DL, Robson MC. Optimizing healing of the acute wound by minimizing complications. Curr Probl Surg. United States; 2007 Nov;44(11):691-763.

[60]. Menke NB, Ward KR, Witten TM, Bonchev DG, Diegelmann RF. Impaired wound healing. Clin Dermatol. United States; 2007;25(1):19-25.

[61]. Davis SC, Ricotti C, Cazzaniga A, Welsh E, Eaglstein WH, Mertz PM. Microscopic and physiologic evidence for biofilmassociated wound colonization in vivo. Wound Repair Regen. United States; 2008;16(1):23-9.

[62]. Gislason H, Gronbech JE, Soreide O. Burst abdomen and incisional hernia after major gastrointestinal operations--comparison of three closure techniques. Eur J Surg. NORWAY; 1995 May;161(5):349-54.

[63]. Penninckx FM, Poelmans S V, Kerremans RP, Beckers JP. Abdominal wound dehiscence in gastroenterological surgery. Ann Surg. UNITED STATES; 1979 Mar;189(3):345-52.

[64]. Pavlidis TE, Galatianos IN, Papaziogas BT, Lazaridis CN, Atmatzidis KS, Makris JG, et al. Complete dehiscence of the abdominal wound and incriminating factors. Eur J Surg. Norway; 2001 May;167(5):351-4; discussion 355

[65]. Humar A, Ramcharan T, Denny R, Gillingham KJ, Payne WD, Matas AJ. Are wound complications after a kidney transplant more common with modern immunosuppression? Transplantation. United States; 2001 Dec;72(12):1920-3.

[66]. Niggebrugge AH, Hansen BE, Trimbos JB, van de Velde CJ, Zwaveling A. Mechanical factors influencing the incidence of burst abdomen. Eur J Surg. NORWAY; 1995 Sep;161(9):655-61.

[67]. Riou JP, Cohen JR, Johnson HJ. Factors influencing wound dehiscence. Am J Surg. UNITED STATES; 1992 Mar;163(3):324-30.

[68]. Webster C, Neumayer L, Smout R, Horn S, Daley J, Henderson W, et al. Prognostic models of abdominal wound dehiscence after laparotomy. J Surg Res. United States; 2003 Feb;109(2):130-7.

[69]. Grande L, Garcia-Valdecasas JC, Fuster J, Visa J, Pera C. Obstructive jaundice and wound healing. Br J Surg [Internet]. John Wiley \& Sons, Ltd.; 1990 Apr 1;77(4):440-2. Available from: http://dx.doi.org/10.1002/bjs.1800770426

[70]. Ahn C, Mulligan P, Salcido RS. Smoking-the bane of wound healing: biomedical interventions and social influences. Adv Skin Wound Care. United States; 2008 May;21(5):227-8.

[71]. Chan LKW, Withey S, Butler PEM. Smoking and wound healing problems in reduction mammaplasty: is the introduction of urine nicotine testing justified? Ann Plast Surg. United States; 2006 Feb;56(2):111-5.

[72]. Rivara FP, Jurkovich GJ, Gurney JG, Seguin D, Fligner CL, Ries R, et al. The magnitude of acute and chronic alcohol abuse in trauma patients. Arch Surg. UNITED STATES; 1993 Aug;128(8):903-7.

[73]. Choudhry MA, Chaudry IH. Alcohol intoxication and post-burn complications. Front Biosci. United States; 2006;11:998-1005.

[74]. Greiffenstein P, Molina PE. Alcohol-induced alterations on host defense after traumatic injury. J Trauma. United States; 2008 Jan;64(1):230-40.

[75]. Radek KA, Kovacs EJ, DiPietro LA. Matrix proteolytic activity during wound healing: modulation by acute ethanol exposure. Alcohol Clin Exp Res. England; 2007 Jun;31(6):1045-52.

[76]. Sabiston Textbook of Surgery-The Biological Basis of Modern Surgical Practice, $19^{\text {th }}$ edition, Elsevier Saunders, 2012 page 299

[77]. T.T. Irvin et al. Abdominal wound healing : a prospective clinical study. Br Med J 1977;351-52.

[78]. Keill RH et al. Abdominal wound dehiscence, Arch Surg 1973; 106:573.

[79]. Lenhardt et al. Perioperative collagen depositin in elderly and young men and women. Arch Surg. 2000; 135:71-74. 
[80]. Israelsson LA, Jonsson T. Overweight and healing of midline incisions: the importance of suture technique. Eur J Surg. NORWAY; 1997 Mar;163(3):175-80.

[81]. Grantcharov TP, Rosenberg J. Vertical compared with transverse incision in abdominal surgery. Eur J Surg 2001 Apr; 167(4):2607.

[82]. Khorgami Z, Shoar S, Laghaie B, Aminian A, Hosseini Araghi N, Soroush A. Prophylactic retention sutures in midline laparotomy in high-risk patients for wound dehiscence: a randomized controlled trial. J Surg Res. United States; 2013 Apr;180(2):238-43.

[83]. Spiliotis J, Konstantino S, Tsiveriotis, Datsis AD, Archodaula, Georgios et al. Wound Dehiscence. World Journal of Emergency surgery 2009; 4:12.

[84]. Soni P, Haripriya VB, Haripriya A, Dutt V. Burst Abdomen: A Post-operative Morbidity in Medical College, Bilaspur,

[85]. India. Int J Sci Stud 2015;3(6):175-178

[86]. Khan MN-S, Naqvi AH, Irshad K, Chaudhary AR. Frequency and risk factor of abdominal wound dehiscence. J Coll Physicians Surg Pak. Pakistan; 2004 Jun;14(6):355-7.

[87]. Aziz a, Alam S, Shaikh I, Manzar S. Abdominal Wound Dehiscence: an Ongoing Dilema. PjsComPk [Internet]. 2009;25(3). Available from: http://www.pjs.com.pk/journal_pdfs/jul_sep09/16-Abdominal Wound Dilema.pdf. 